\title{
Meeting Report: 18th International Meeting of the Danubian League against Thrombosis and Haemorrhagic Disorders
}

\author{
Peter Kubisz, MD, DSc ${ }^{1}$ Danijela Mikovic, MD, $\mathrm{PhD}^{2}$ \\ ${ }^{1}$ National Center of Hemostasis and Thrombosis, Clinic of Hematology \\ and Transfusiology, Comenius University in Bratislava, Martin \\ University Hospital, Martin, Slovak Republic \\ ${ }^{2}$ Haemostasis Department with Registry of Inherited Bleeding \\ Disorders, Blood Transfusion Institute of Serbia, Belgrade, Serbia \\ ${ }^{3}$ Institute of Nuclear Medicine, ISOTOPIX, Vienna, Austria
}

Semin Thromb Hemost 2015;41:903-906.

\author{
Lucia Stanciakova, $\mathrm{MD}^{1}$ Helmut Sinzinger, MD, $\mathrm{PhD}^{3}$
}

Address for correspondence Peter Kubisz, MD, DSc, National Center of Hemostasis and Thrombosis, Clinic of Hematology and Transfusiology, Comenius University in Bratislava, Jessenius Faculty of Medicine and University Hospital in Martin, 03659 Martin, Slovak Republic (e-mail: kubisz@jfmed.uniba.sk).
Maintaining the tradition of past events, the 18th International Meeting of the Danubian League against Thrombosis and Haemorrhagic Disorders (DLTH) was held in the multicultural and fascinating city of Sarajevo, Bosnia and Herzegovina, from May 14 to 16, 2015. As underscored in the Congress welcome message, and reflecting on the past Danube meeting aiming to join a multitude of countries and people together, the Sarajevo meeting was organized with respect to multidisciplinary considerations to provide information on up-to-date scientific discoveries and practical experience within the wide spectrum of thrombosis and hemorrhagic disorders. Many new insights into issues related to platelets, coagulation and inhibitors, fibrinolysis, thrombotic disorders, and vascular biology were therefore provided. The cross-sessional scientific program is still available at the webpage (http://www.danubianleaguesarajevo.com/pdf/DLTH-2015-Final-program.pdf). Prestigious guests from not only the countries down the Danube but also from all over the world attended the meeting. Altogether, 53 lectures, including 16 state-of-the-art lectures and presentations, were given during 4 satellite symposia and 61 posters were presented.

\section{Day 1 of the Meeting: Sessions on Thrombosis, Sticky Platelet Syndrome, von Willebrand Disease, and Rare Bleeding Disorders}

Starting the opening session of the meeting, Prof. Jan Jacques Michiels, MD, PhD (Rotterdam, The Netherlands), underlined the importance of the evaluation of D-dimers in the diagnostic algorithm of deep venous thrombosis. Following the lecture of Darko Antic, MD, PhD (Belgrade, Serbia), the talks in this session were directed toward the association between the results of laboratory tests and the treatment approach to thrombotic complications of hematologic neoplasms.

The markedly interesting hallmark of this session was the thrombophilic thrombocytopathy described as sticky platelet syndrome (SPS). The first lecturer on this topic was by the President of the DLTH, Prof. Peter Kubisz, MD, DSc (Martin, Slovakia), who dedicated his presentation to Prof. Eberhard F. Mammen, MD, founder, and first editor-in-chief of the journal Seminars in Thrombosis E Hemostasis. The clearly defined and internationally accepted clinical and laboratory criteria of SPS and also the results of the genetic analysis performed in the largest cohort of the patients with SPS from the National Center of Hemostasis and Thrombosis, Martin, Slovakia, were subsequently presented by various speakers. Last but not least, the current possibilities for treatment of the life-threatening clinical manifestations of SPS were outlined by Guillermo J. Ruiz-Argűelles, MD, FRCP (Glasg), MACP (Puebla, Mexico).

Special attention was also granted to the condition von Willebrand disease (VWD), representing the most commonly inherited bleeding disorder. Emmanuel J. Favaloro, PhD, MAIMS, FFSc (RCPA) (Sydney, Australia), presented his experience related to the errors in the laboratory identification of VWD, and concluded that the best way to improve patient management is to improve its identification using a wide panel of laboratory assays to evaluate the different functions of von Willebrand factor (VWF). A specific focus of this presentation was the addition of newly emerging tests. The audience then heard about additional experiences with the use of VWF multimer testing and genetic analysis in diagnosing VWD and also the novel trends in the treatment of gastrointestinal complications of the disease. Danijela published online October 19, 2015
Issue Theme Current Issues in Hemophilia: Recognizing Clinical Heterogeneity, Replacement Therapy and Outcome Assessment; Guest Editor: Alok Srivastava, MD, FRACP, FRCPA, FRCP.
Copyright $\odot 2015$ by Thieme Medical Publishers, Inc., 333 Seventh Avenue, New York, NY 10001, USA.

Tel: +1(212) 584-4662.
DOI http://dx.doi.org/ 10.1055/s-0035-1564803. ISSN 0094-6176. 
Mikovic, MD, PhD, the Secretary General of the DLTH Meeting (Belgrade, Serbia), then gave a comprehensive introduction into the fascinating world of rare bleeding disorders. One of the rarer bleeding disorders globally, afibrinogenemia, along with an unusual case report was presented separately.

The pleasant and essential part of each conference-the Opening Ceremony-was initiated that evening by the speech of the President of DLTH, Co-President of the DLTH Meeting Meliha Vila, MD (Sarajevo, Bosnia and Herzegovina), Honorary President, Prof. Helmut Sinzinger, MD, PhD (Vienna, Austria), and the Secretary General Danijela Mikovic, MD, PhD (Belgrade, Serbia). They addressed the participants and welcomed them to the exciting and multidisciplinary sessions. In addition to the official part of the opening ceremony, the performance of the singers dressed in traditional Bosnian costumes provided further interest (-Fig. 1).

\section{Day 2: Sessions on Thrombosis (Risk Factors and Treatment), Women and Hemostasis, and Principles of Hemophilia Care}

The pros and cons of thrombophilia testing in specific clinical situations were outlined in the lecture given by Prof. Frits $R$. Rosendaal, MD, PhD (Leiden, The Netherlands). Further presentations provided a wide experience of possibilities related to laboratory monitoring of anticoagulants/antithrombotics, with particular emphasis on clinical practice and treatment strategies. Useful experiences with patients at high risk of bleeding using the newer direct oral anticoagulants or those requiring reperfusion therapy because of pulmonary thromboembolism were provided by Ahmet Muzaffer Demir, Prof., MD (Edirne, Turkey) and Slobodan Obradovic, MD, PhD (Belgrade, Serbia), respectively. Opened by the state-of-theart lecture on thrombotic thrombocytopenic purpura and pregnancy, given by Prof. Flora Peyvandi, MD, PhD (Milan, Italy), a separate theme of thrombophilia was presented in the context of the prothrombotic sensitive group of pregnant women and females taking oral contraceptives.

The DLTH assembly was held during lunch, at which time the delegates elected Meliha Vila, MD, to be the new president of the DLTH 2015, and the current president, Peter Kubisz, Prof., MD, DSc, became the honorary president of the league.

The next topic that grew progressively during the meeting was the management of hemophilia. Prof. Paul Giangrande, BSc, MD, FRCP (Lon., Edin., and Ireland), FRCPath, FRCPCH (Oxford, Great Britain), provided novel insights into the treatment of hemophilia with a focus on long acting factor VIII and IX molecules and also the potentially curative outcome with gene therapy in hemophilia. The availability of factor concentrates has improved. Therefore, as underlined by Prof. Bulent Zulfikar, MD (Istanbul, Turkey), surgical procedures in hemophiliacs can now be performed without any significant complications, provided appropriate and comprehensive hematologic preparation is

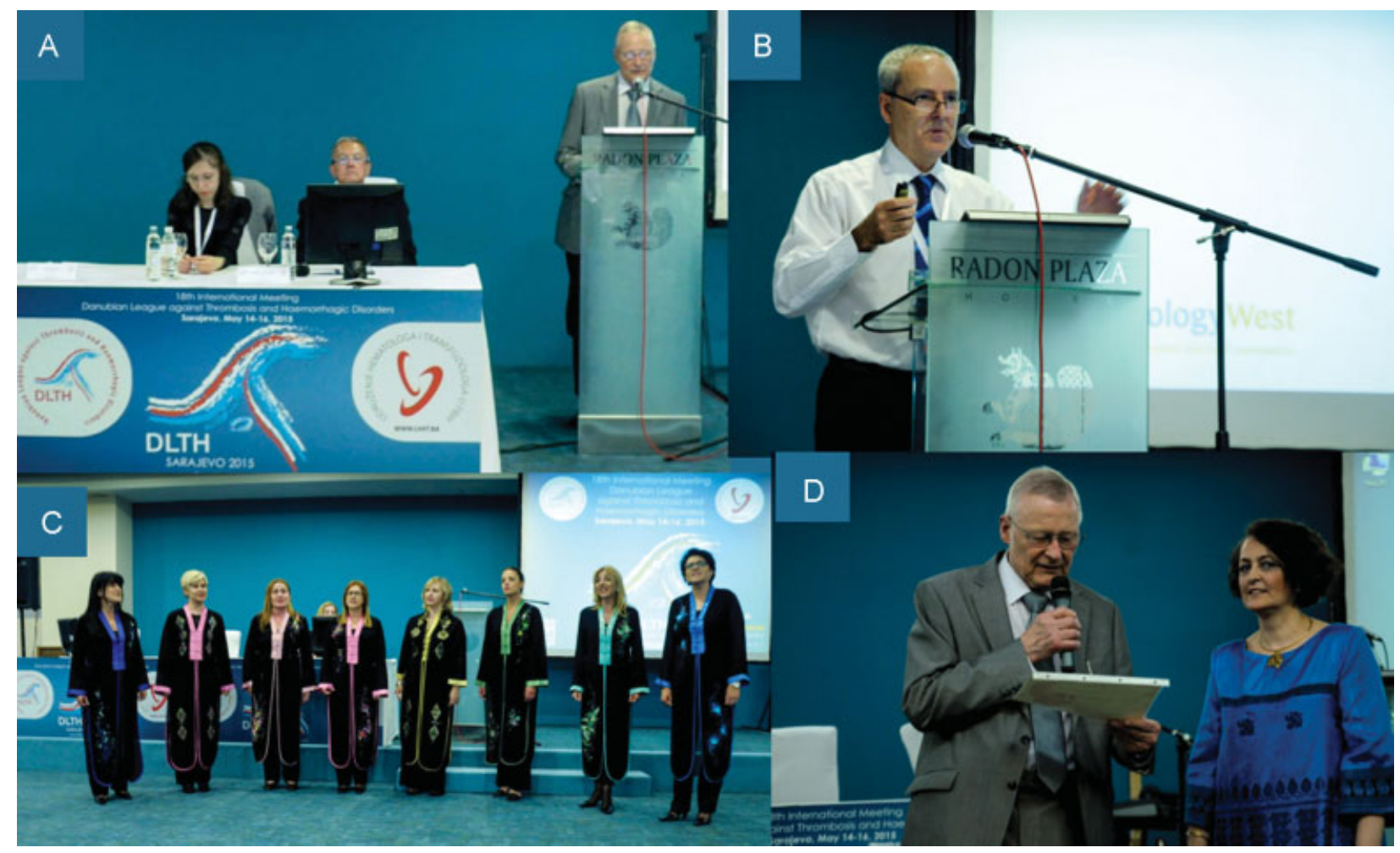

Fig. 1 Some memorable moments from the 1st day of the meeting: (A) Prof. Peter Kubisz, MD, DSc, presenting the historical perspective of sticky platelet syndrome. (B) Emmanuel J. Favaloro, PhD, MAIMS, FFSC (RCPA), and his lecture on "real-world" errors in the laboratory identification of von Willebrand disease. (C) The original vocal performance of talented Bosnian singers. (D) The President and Secretary General of the Danubian League against Thrombosis and Haemorrhagic Disorders at the Opening Ceremony. 


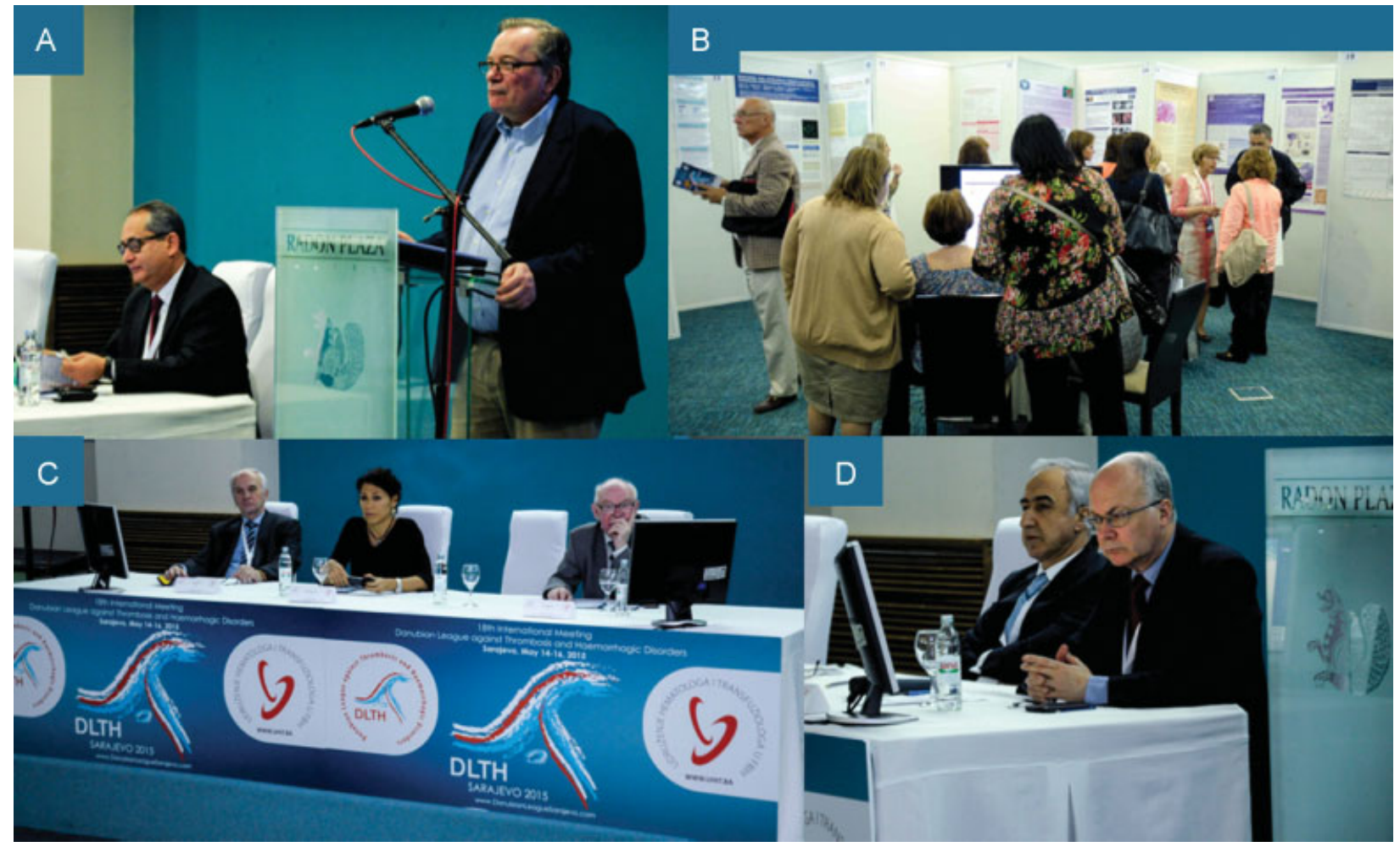

Fig. 2 Some memorable moments captured from the 2 nd day of the conference: (A) Prof. Frits R. Rosendaal, MD, PhD, and his lecture on the indications of thrombophilia testing. (B) Meeting attendees passing by the posters. (C) The chairs of the session entitled "Women and haemostasis" Prof. Flora Peyvandi, MD, PhD; Prof. Ivo V. Elezovic, MD, PhD, and Prof. Igor N. Bokarev, MD, PhD. (D) The chairmen of the session Principles of Hemophilia Care-Prof. Paul Giangrande, BSc, MD, FRCP (Lon., Edin., and Ireland), FRCPath, FRCPCH, and Prof. Bulent Zulfikar, MD.

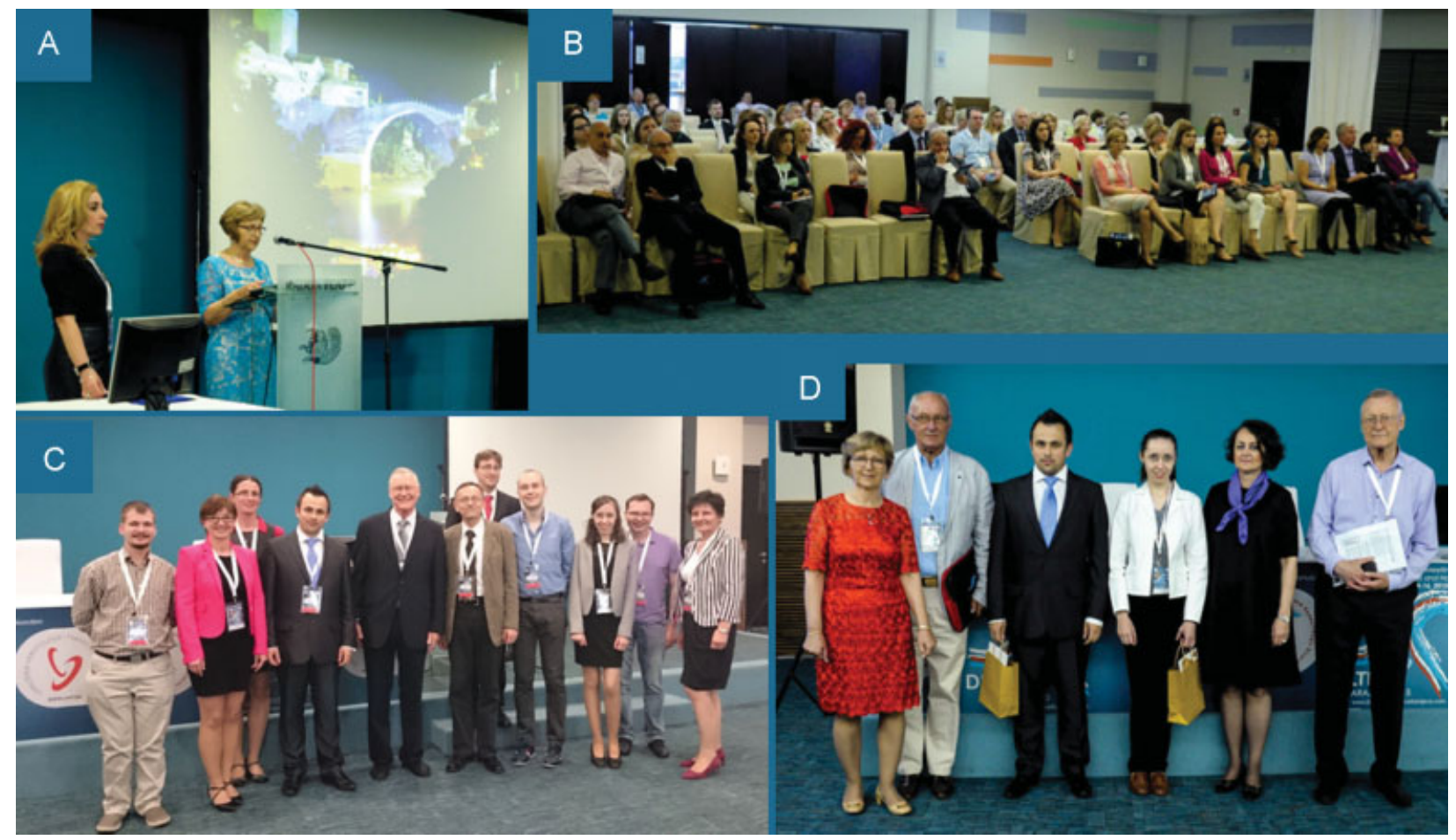

Fig. 3 Some interesting events of the 3rd day of the meeting: (A) The incoming President of the Danubian League against Thrombosis and Haemorrhagic Disorders, Meliha Vila, MD (B) The audience at the scientific program. (C) The extraordinary research team from Martin, Slovakia. (D) The winners of the Young Investigator Award with the Award committee-from the left: Meliha Vila, MD, Honorary President of the meeting Prof. Helmut Sinzinger, MD, PhD, Tomas Simurda, MD, Lucia Stanciakova, MD, Danijela Mikovic, MD, PhD; and Prof. Peter Kubisz, MD, DSc. 
undertaken. Several other lecturers discussed the most frequent adverse effect of hemophilia treatment, namely inhibitor development, and therapeutic strategies to inhibitor eradication.

The traditional poster session, involving presentations in printed or electronic form, was also organized in addition to the lectures (-Fig. 2). The highlights of the conference and open willingness to exchange individual experiences provoked a continuation of scientific discussion during the evening gala dinner. At this occasion, the authors of the best poster-Emina Suljovic-Hadzimesic, MD, M.Sc. (Sarajevo, Bosnia and Herzegovina) and Roman Kotlin, M.Sc., M.E., B.Ed., PhD (Prague, Czech Republic)-were awarded the "Helmut Vinazzer" Award.

\section{Day 3: Sessions on Vascular Biology, Periodontal Disease and Hemostasis, and Clinical Hemostasis}

The first session was related to vascular biology. If some of the attendees initially considered stem cells to be predominantly a subject of transplant in the treatment of hematologic malignancies, they additionally learnt about the outstanding effects of therapeutic angiogenesis performed in patients with critical limb ischemia from Martin, Slovakia. The subsequent session was aimed to present the most important hemostatic issues in relation to periodontal disease.

Following the presentation of Nebojsa M. Antonijevic, MD, M.Sc., PhD (Belgrade, Serbia), subsequent lectures confirmed that the use of not only the so-called "point-of-care" methods, such as rotational thromboelastometry, but also the routine hemostatic tests could be of importance in the evaluation of disorders of hemostasis in surgical and gynecological patients or those with internal disease. During the meeting, four satellite symposia were arranged interactively.

The Closing Ceremony represented temporal space for summarizing. We would like to convey our gratitude and thank all the attendants for their participation. The authors of the best lecture-Lucia Stanciakova, MD, and Tomas Simurda, MD-were awarded the Young Investigator Award of DLTH (-Fig. 3). As a postscript, we also later learnt that seven young investigators from this meeting were also nominated for the Seminars in Thrombosis \& Hemostasis Eberhard F. Mammen Young Investigator Award, with the announcement of the award winners to be made at a later date.

We sincerely hope that the attendance at the conference was beneficial for everyone with the possibility to attend highquality lectures, broaden the scientific horizon, and, last but not least, provide further inspiration for future scientific work. Finally, the organizers expressed their wish that the meeting will continue in the future with the invitation to the 19th International Meeting of the DLTH in Skopje, Macedonia, in 2017.

\section{Acknowledgments}

We would like to cordially thank the organizing and scientific committee of the DLTH and Society of Hematologists and Transfusiologists in the Federation of Bosnia and Herzegovina for their cooperation. Financial and material support was provided by: Alkaloid AD Skopje, Amgen, Aspen, Bayer HealthCare, Farma d.o.o., Gaudi Lufthansa City Center, Grifols, Novo Nordisk, Octapharma, Pfizer, Sanofi, and Stago. 